\title{
Short-Term Radiological Comparison Study between Intervertebral Cage and Dynamic Cervical Implant for Management of Cervical Disc Disease
}

\author{
ESAM R. ALGEHAWY, M.D.*; MOHAMED B. ABDEL SALAM, M.D.*; MOHAMED M. MOHIELDIN, M.D.*; \\ EHAB M. ABDEL GHAFAREISSA, M.D.*; HAMDI N. MOSTAFA, M.D.** and \\ SALAMA G. KORAITIM, M.D.*
}

The Department of Neurosurgery, Faculty of Medicine, Cairo University* and Misr University for Science \& Technology**

\begin{abstract}
Background: This study details the evaluation by radiological outcome of dynamic cervical replacement for management of cervical disc diseases compared to PEEK cage insertion.

Aim of Study: The study aims to compare the radiological outcome of two modalities for the treatment of the cervical disc diseases, the first group is the fixed group (treated by insertion of inter vertebral cages), and the second group is the dynamic one, (treated by insertion of the dynamic cervical implants or DCI).

Patient and Methods: A prospective study conducted on 50 patients with cervical disc diseases lesions treated either by fixed or dynamic prosthesis; the outcome of both methods was confirmed and evaluated by radiological assessment.

Results: The average age of presentation was 44.1 years for both groups, female ratio for the fixed group was 1.5:1, and 1:1.08 for the dynamic group, with age ranged between 35 and 53 years for both studies with an average of $44.1 \pm 6.345$ years. The average follows-up period in our study was 22.5 months, 21 cases had left sided radiculopathy, 10 cases had right sided affection. Most common operated level was C56 for both groups.

Conclusion: The DCI implant offers stable, controlled (adequate) motion the DCI implant is a safe and easy procedure. Immediate dynamic stability with good clinical and radiological response. The DCI implant is the alternative to cage fusion with no implant-related morbidity or complications to already significantly degenerated motion segments.
\end{abstract}

Key Words: Range of motion - Adjacent segment disease Heterotopic ossification.

\section{Introduction}

ONE of the primary goals of cervical dynamic implants is to reproduce normal kinematics after

Correspondence to: Dr. Esam R. Algehawy, The Department of Neurosurgery, Faculty of Medicine, Cairo University implantation. Another study showed the preservation of motion in cervical dynamic implants treated spinal segments [4].

Titanium, carbon fiber, and PEEK are most commonly used material for cage production. The use of a titanium cage may lead to vertebral body collapse if the end plate is over degraded during discectomy [2]

Cervical dynamic implants an exciting new technique in the management of cervical radiculopathy and myelopathy. Cervical dynamic implants offer many distinct advantages over the traditional ACDF to include preserved segmental motion, decreased adjacent level strain, and improved outcomes [9].

The cost of disc cervical dynamic implants was comparable to cage and plate. The benefit with cage only group was largely driven by shorter operative time and shorter hospital stay [18]. Titanium, carbon fiber, and PEEK are most commonly used material for cage production. The use of a titanium cage may lead to vertebral body collapse if the end plate is over degraded during discectomy $\left[{ }^{2}\right]$.

The Dynamic Cervical Implant stabilizes the cervical spine while providing controlled motion in flexion-extension, which is the main motion in sub axial cervical spine. Shock absorption, a main advantage compared to most existing prostheses, prevents adjacent accelerated degeneration [7].

\section{Patients and Methods}

This study was conducted at Department of Neurosurgery, Faculty of Medicine, Cairo University from 2011 to 2013. 
Prospective study conducted 50 patients with single or multiple level cervical disc diseases like herniated or degenerative lesions treated either by fixed prosthesis or dynamic prosthesis, the outcome of both methods was confirmed by radiological assessment through Plain cervical X-rays, computerized tomography with coronal and sagittal reconstruction views and MRI of the cervical spine.

\section{Inclusion criteria:}

Inclusion criteria included cervical disc disease from $\mathrm{C} 3$ to $\mathrm{C} 7$; including disc herniation, degenerative discopathy and discogenic stenosis, mobile, cervical segments with. These patients will be selected specifically and divided into two groups, in order to compare them statistically. Specifically selected and divided randomly into two groups: Fixed group (A) treated by cage insertion, and the dynamic group (B) will undergo surgical replacement by dynamic cervical implants (DCI).

\section{Exclusion criteria:}

Obvious instability of cervical vertebra, cervical trauma, tumors, Infection of cervical vertebra or disc spaces, Metabolic bone diseases serious osteoporosis, rheumatoid arthritis and contraindications of anesthesia.

The operative procedures for both fixed and dynamic methods:

The target cervical level is identified by fluoroscopy, Supine position under general anesthesia with the extremities padded and protected. The neck is moderately hyperextended with the head placed in a headrest. A roll can be placed under the inter scapular area to obtain greater extension [5].

A transverse incision is made along a skin crease. When multilevel disciectomy are being considered, the border of the sternocleidomastoid is incised obliquely. The platysma muscle is divided sharply either along its fibers or along the axis of the transverse incision $[1,2]$.

Underneath the platysma muscle the medial border of the sternocleidomastoid is identified. The muscle may be mobilized with blunt dissection and retracted laterally. The laryngeal strap muscles are also identified and carefully mobilized medially [3].

After the sternocleidomastoid muscle is mobilized, the surgeon can feel the pulsations of the carotid artery with digital palpation. The carotid sheath is retracted laterally with Cloward retractors, and the trachea and esophagus are retracted medially. Once the correct level is identified, the longus coli muscle is dissected laterally off the anterior vertebral body with bipolar cauterization and periosteal elevators. Once the muscle is mobilized, self-retaining retractors are placed with the teeth of the retractor underneath the muscle [1]. Fig. (1).

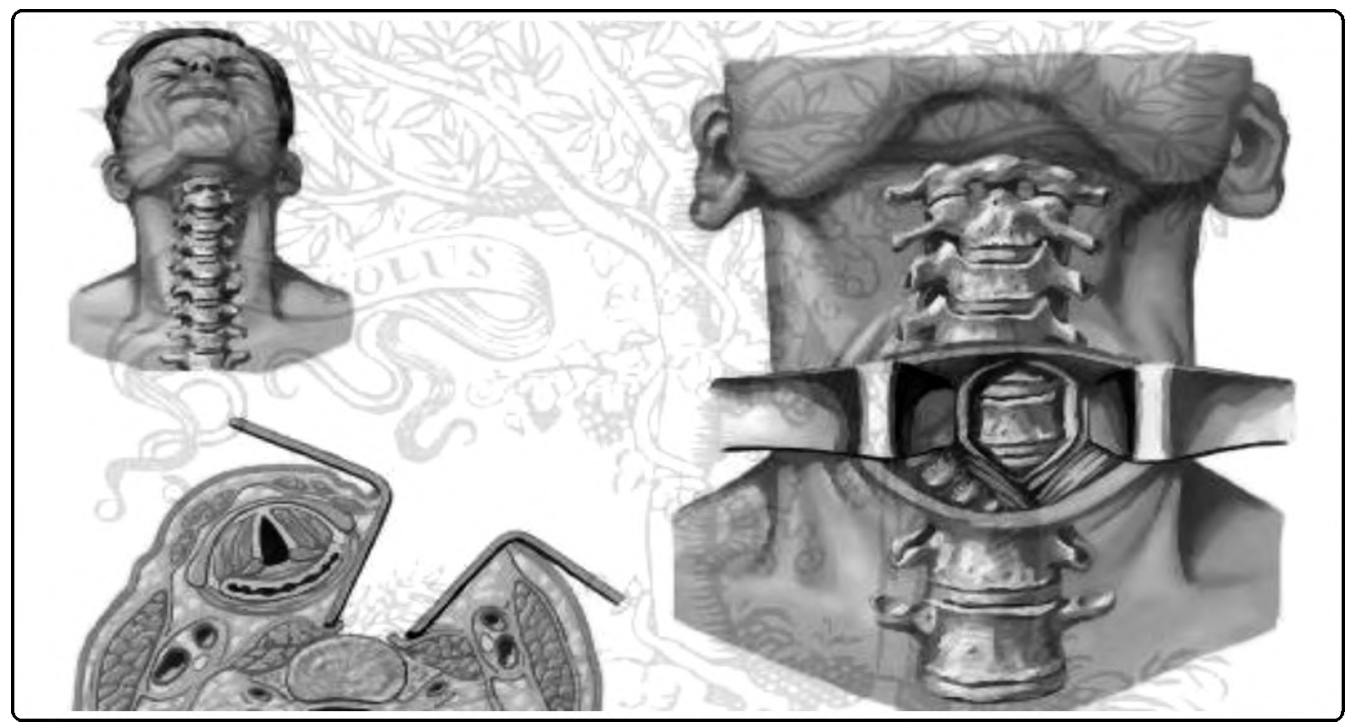

Fig. (1): Cervical muscles mobilization and disc identification.

Caspar distracting pins can be placed at the midlevel of the vertebral body to obtain adequate exposure and provide distraction to facilitate identification of the intervertebral space [2].

\section{Insertion of the intervertebral device:}

\section{1- Cage insertion:}

The anterior aspect of the annulus fibrosis is removed circumferentially with a sharp knife. The 
superficial disc is resected with curettes. The Luschka joints are excellent anatomic landmarks that help the surgeon avoid inadvertent injury to the vertebral artery, which lies immediately lateral to the joint. Once the PLL is identified, we remove it to determine whether any sub ligamentous disc material is present. it can be resected safely with upgoing curettes or small Kerrison punches [4].

A circular hole 10 to $14 \mathrm{~mm}$ deep and 12 to $16 \mathrm{~mm}$ in diameter is done for preparing the disciectomy site [5].

Polyetheretherketone (PEEK) cage is a semi crystalline aromatic polymer that is used as a structural spacer to maintain the disc and foraminal height. Recombinant human bone morphogenetic protein-2 (rhBMP-2) has been used in conjunction with synthetic materials such as PEEK to increase the rate of fusion with good results [1]

Meticulous attention is needed to measure the height of the graft accurately and to modify it to preserve normal cervical lordosis. Careful preparation of the end plate ensures successful incorporation of the graft and prevents it from being dislodged. After the graft is placed, the distraction is removed slowly to provide compression along the cage [6].

Patients undergoing one-level disciectomies seldom require a hard-cervical collar after surgery while patients with multilevel discectomies are usually maintained in a hard collar for approximately 6 weeks [3]
Cervical radiographs in flexion and extension views are obtained to assess incorporation of the graft [6].

\section{2- DCI insertion: \\ DCI:}

The DCI implant has an omega shape which was designed to fit to the lateral anatomical view of the disc and the adjacent endplates. It is a onepiece anatomical-shaped, self-fixing dynamic spacer made of titanium, easy to implant like a cage.

Being a single-piece implant, it has excellent fatigue strength with no wear debris. The implant auto-stabilize itself by engaging the anteriorly placed teeth of the implant in the endplates of the vertebra above $\&$ below [7]

The DCI implant was developed in 2002 by Dr. Guy Matgé, Luxembourg. A total of 12 patients were implant with the original device (first generation). Initially, the device was marketed by Fixano SAS (Péronnas, France) and the transfer of ownership to Paradigm Spine was finalized in early 2005. The DCITM was CE-marked by Paradigm Spine and the design was further optimized to better accommodate the implant to the anatomy [2].

This second generation the footprint was changed from square to rectangular and more sizes were added. Fig. (2).

Implant Size Overview

- 3 Implant heights for appropriate height restoration.

- 4 Different footprints for proper endplate coverage.
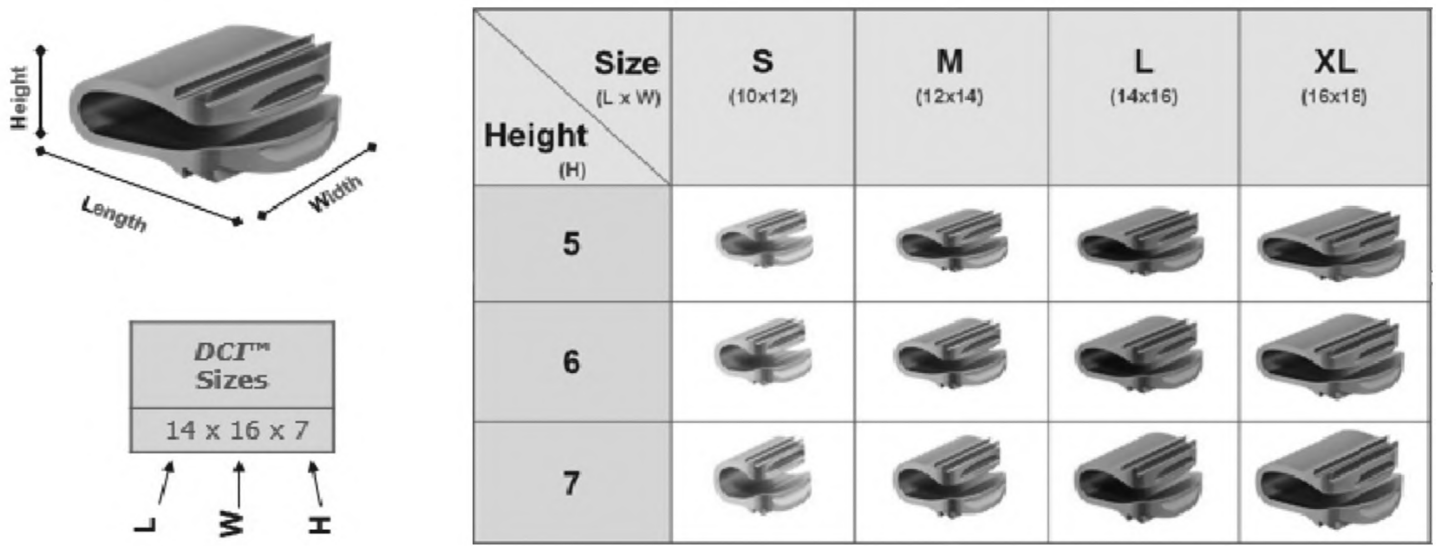

Fig. (2): Sizes of the DCI device.

\section{Surgical technique:}

With cervical discectomy and endplate cleaning is careful to respect cartilage and avoid bony bleeding $[\mathbf{5 , 8 ]}$.
It is important not to remove anterior osteophytes preventing heterotopic ossification. Internal foraminotomy is an important step in radiculopathy cases together with posterior longitudinal ligament 
(PLL) resection for optimal decompression in myelopathy cases. Trial implants are then utilized to define the appropriate implant size. Exact size selection is most important to avoid migration. The general guideline for optimal implant sizing is selecting the implant with the maximum width and a proper height as needed for appropriate restoration of the segment [7,9].

Implant positioning is centered at midline with maximum endplate coverage for optimal stress distribution where the trial is centered at the midline of the medial-lateral diameter of the vertebral body $[10,11]$

The DCI inserter is used to insert the DCI device for protection of endplate surface due to reduced implant height during insertion and the use of depth stop for accurate positioning. By the use of the depth stop an optimal insertion depth of $2-3 \mathrm{~mm}$ inside the anterior and posterior border can be measured. This is verified under fluoroscopic control [7].

It is recommended to place the implant as far as posterior to fit the concavity of the inferior endplate of the superior vertebral body. The trials with depth control facilitate ideal positioning. Slight compression on CASPAR distractor stabilizes further the implant by engaging teeth in the endplates [5,8]. Fig (3).
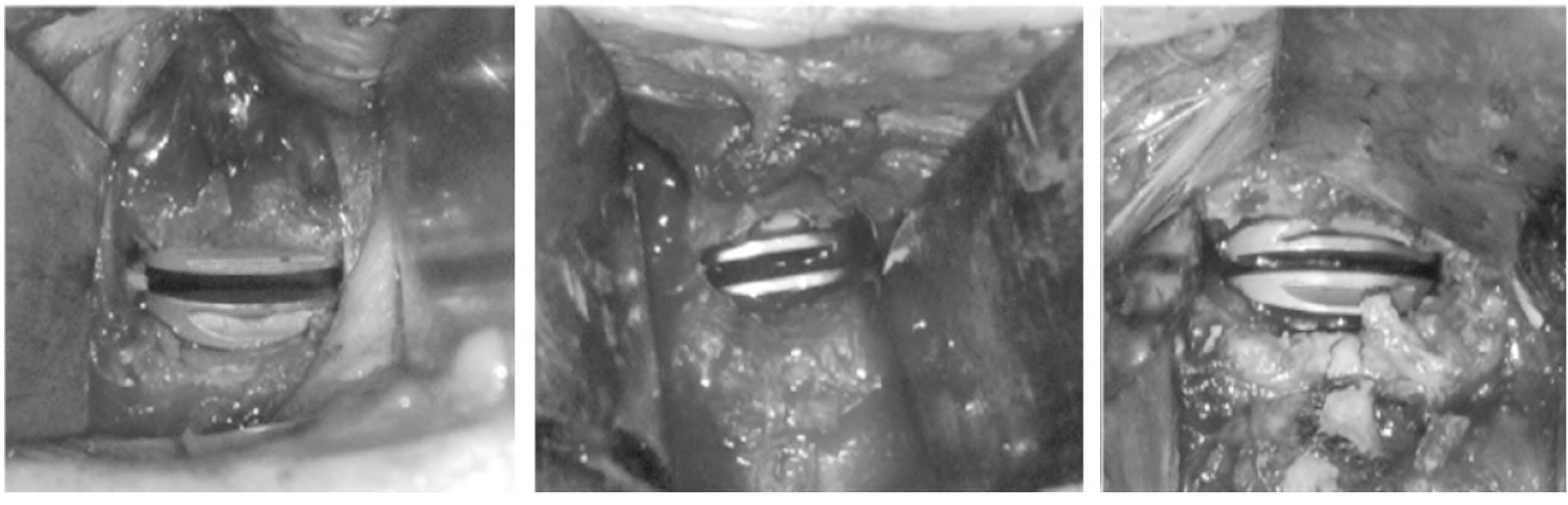

Fig. (3): Intra-operative view for DCI insertion.

The post-operative follows-up:

Patients can normally be mobilized the next day, avoiding excessive cervical motion. Postoperative pain killers, regular follow-up [12] .

\section{Radiological evaluation:}

Plain cervical X-rays for all cases, including antero-posterior view, dynamic views to assess stability, oblique views and the standard lateral view to assess curvature, sagittal rotation and alignment.

Computerized tomography with coronal and sagittal reconstruction. MRI of the cervical spine as well as dynamic views are systematically performed.

\section{Results}

\section{Statistical analysis:}

The collected data were presented as mean (SD), numbers and percentages as appropriate. Categoriçal variables were analyzed using Chisquare $\left(\chi^{2}\right)$ test. Continuous variables were tested using unpaired student's $t$-test. Statistical analysis was performed using R Package (Version 3.0.2). $p$-value $<0.05$ is considered statistically significant.

\section{Patient data:}

This study included 50 had cervical disc diseases divided into two groups, the fixed group (A), were they are 15 males and 10 females. In addition, the dynamic group (B) were they are 12 males and 13 females, their age ranged from 35 to 53 years with a mean of 44.1 and median of 44.5 years with standard deviation of \pm 6.345 years, for both group,

Within the group study, the levels of the surgery are distributed from the cervical vertebra $\mathrm{C} 3$ to $\mathrm{C} 7$, levels that are more common are C4-5 and C56 . In addition, the double level surgery is the same for both groups of study groups. Table (1).

Table (1): The patient's data.

\begin{tabular}{lllc}
\hline Demographic data & $\begin{array}{l}\text { Fixed } \\
\mathrm{n}=25\end{array}$ & $\begin{array}{c}\text { Dynamic } \\
\mathrm{n}=25\end{array}$ & $p$-value \\
\hline Male/female ratio & $15: 10$ & $12: 13$ & 0.57 \\
Age, in years: & & & \\
$\quad$ Range & $35-53$ & $35-53$ & \\
$\quad$ Mean (SD) & $44(4.6)$ & $43(5.1)$ & 0.47 \\
Disc level: & & & \\
C 3,4 & 4 & 5 & 0.932 \\
C 4,5 & 6 & 7 & \\
C 5,6 & 9 & 8 & \\
C 6,7 & 3 & 2 & \\
Double level & 3 & 3 & \\
\hline
\end{tabular}




\section{Outcome:}

\section{The heterotopic ossifications:}

Although cervical spondylosis affects the entire cervical spine, the greatest arthritic changes develop between the fifth and sixth and between the sixth and seventh cervical vertebrae. Symptomatic adjacent segment disease also was most common at these levels. Lateral radiographs with the cervical spine in flexion and extension were made at each follow-up visit until the evident radiological changes are observed [16].

Follow-up after anterior cervical surgery shows additional radiologic degeneration at the adjacent disc levels, often reflecting a clinical deterioration. The severity of this additional degeneration correlated with the time interval since surgery and the severity of the degenerative changes [17].

For the late radiologic follow-up, a lateral x-ray was made. This X-ray was compared with an early $\mathrm{X}$-ray, obtained in the immediate preoperative or postoperative period. The degrees of disc narrowing and of anterior osteophyte formation at the superior and inferior adjacent levels were assessed. [20]

The 5-grade scale of severity of heterotopic ossification: [19]

- Grade 0: No heterotopic ossification present.

- Grade 1: Heterotopic ossification present, but only as islands of bone without affecting the intervertebral space.

- Grade 2: Heterotopic ossification with new bone formation present in the disc space, without blocking or articulating between the adjacent level endplates.

- Grade 3: Describes bridging ossifications, however, with movement of the prosthesis still possible, but a limited range of motion.

- Grade 4: Complete bony amyloses or fusion without movement of the TCDR in active flexion and extension.

\section{The adjacent level disease:}

The Adjacent segment degeneration ASD (or adjacent level disease), is condition that often occurs after the spinal fusion. ASD affects the intervertebral disc, the end plates, inter vertebral ligaments and joint(s) above and below the area addressed by the surgery where it was normal at time of surgery, ASD can occur anywhere along the spine. While symptomatic adjacent segment disease is defined as the development of new radiculopathy, myelopathy, or myelopathy referable to a motion segment adjacent to the site of a previous anterior arthrodesis of the cervical spine [16]
The diagnosis of symptomatic adjacent segment disease was based on the presence of new radicular or myelopathic symptoms referable to an adjacent degenerated level on two consecutive visits [18]

We also found a close correlation between the risk of symptomatic adjacent-segment disease and the magnitude of motion at a given level, as described by White and Panjabi. Cervical motion segments with a greater range of motion had a higher prevalence of adjacent segment disease. Degenerative changes at the most mobile segments of the cervical spine may be part of the biological process of progressive cervical spondylosis and unrelated to an adjacent arthrodesis [20]

\section{Discussion}

\section{The heterotopic ossifications:}

For the late radiologic follow-up, a lateral Xray was made. This $\mathrm{X}$-ray was compared with an early X-ray, obtained in the immediate preoperative or postoperative period. The degrees of disc narrowing and of anterior osteophyte formation at the superior and inferior adjacent levels were assessed. Table (2).

Table (2): The heterotopic ossifications results within the two groups.

\begin{tabular}{|c|c|c|c|c|c|c|}
\hline \multirow{2}{*}{$\begin{array}{l}\text { Heterotopic } \\
\text { ossification }\end{array}$} & \multicolumn{2}{|c|}{ Fixed } & \multicolumn{2}{|c|}{ Dynamic } & \multirow{2}{*}{$\begin{array}{c}p \text {-value at } \\
\text { one year }\end{array}$} & \multirow{2}{*}{$\begin{array}{c}p \text {-value at } \\
\text { two year }\end{array}$} \\
\hline & $\begin{array}{l}\text { One } \\
\text { year }\end{array}$ & $\begin{array}{l}\text { Two } \\
\text { years }\end{array}$ & $\begin{array}{l}\text { One } \\
\text { year }\end{array}$ & $\begin{array}{l}\text { Two } \\
\text { years }\end{array}$ & & \\
\hline None & 10 & 0 & 22 & 20 & 0.001 & $<0.001$ \\
\hline Grade I & 10 & 10 & 3 & 4 & & \\
\hline Grade II & 5 & 9 & 0 & 1 & & \\
\hline Grade III & 0 & 6 & 0 & 0 & & \\
\hline Grade IV & 0 & 0 & 0 & 0 & & \\
\hline
\end{tabular}

The collected data had showed no there were no significant statistical results, between the both study groups for the first year follow-up. While two-year follow-up had showed a significant statistical results, seen at the level of surgery and the adjacent segments to the target level, Fig. (4).

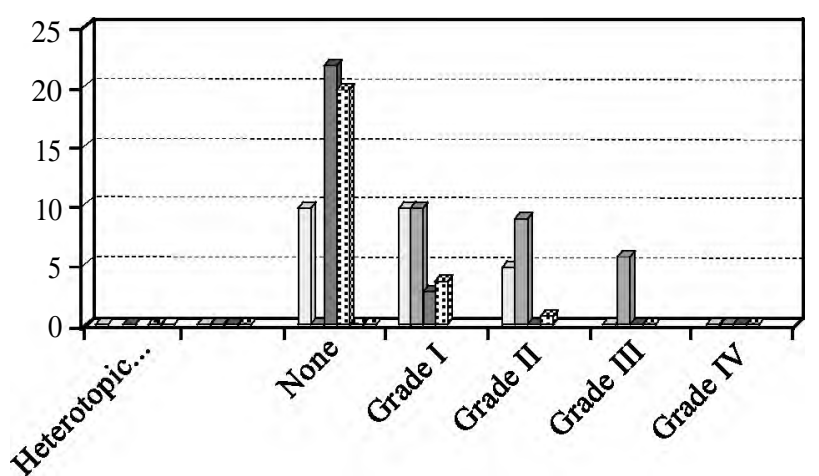

Fig. (4): The Heterotopic Ossifications within the two groups. 
With the study of the range of motion, it was observed that for the fixed group at the site of disc surgery shows decrease by about $90 \%$ for the both planes flexion-extension and lateral bending, and increased at the adjacent site about $30 \%$ for flexionextension and about $15 \%$ increase for lateral bending. For the dynamic group, at the operative site the flexion-extension increase by about $10 \%$, while lateral bending decrease by about $10 \%$ and lateral bending decrease by about $30 \%$, Table (3).

Table (3): The adjacent level disease within the two groups.

\begin{tabular}{lccc}
\hline Adjacent level disease & $\begin{array}{c}\text { Fixed } \\
\mathrm{n}=7\end{array}$ & $\begin{array}{c}\text { Dynamic } \\
\mathrm{n}=0\end{array}$ & $p$-value \\
\hline After one year & 0 & 0 & 1 \\
After two years & 7 & 0 & 0.001 \\
\hline
\end{tabular}

There was significant result seen as preserved cervical motion at the level of the surgery seen within the dynamic group compared to the fixed one.

\section{The adjacent level disease:}

The Adjacent segment degeneration ASD (or adjacent level disease), is condition that often occurs after the spinal fusion. ASD affects the intervertebral disc, the end plates, inter vertebral ligaments and joint(s) above and below the area addressed by the surgery where it was normal at time of surgery. The diagnosis of symptomatic adjacent segment disease was based on the presence of new radicular or myelopathic symptoms referable to an adjacent degenerated level on two consecutive visits [17].

Therefore, the result is significantly showing the occurrence of the adjacent level disease with the fixed group more than the dynamic group, which enforce us for reoperation for the target, level correlating the clinically relapsing complains [21].

The addition of anterior cervical fixation at the time of fusion, which may help to maintain lordosis, lower pseudarthrosis rates, and decrease the need for postoperative cervical collars, has been associated with dysphagia, screw back out, or implant failure, among other complications. When assessing the biomechanical consequences of fusion there was changes at levels adjacent to a fused segment, including increased shear strains, higher intradiscal pressures, and increased adjacent segment motion. Table (4) $[19,20]$.

Table (4): ROM at operative and adjacent motion segment units.

\begin{tabular}{|c|c|c|c|c|}
\hline & \multicolumn{2}{|c|}{ Fixed group } & \multicolumn{2}{|c|}{ Dynamic group } \\
\hline & In flexion, extension & Lateral bending & In flexion, extension & Lateral bending \\
\hline At operative site & $90 \%$ decrease & $90 \%$ decrease & $10 \%$ increase & $25 \%$ decrease \\
\hline At the adjacent level & $30 \%$ increase & $15 \%$ increase & $10 \%$ decrease & $30 \%$ decrease \\
\hline
\end{tabular}
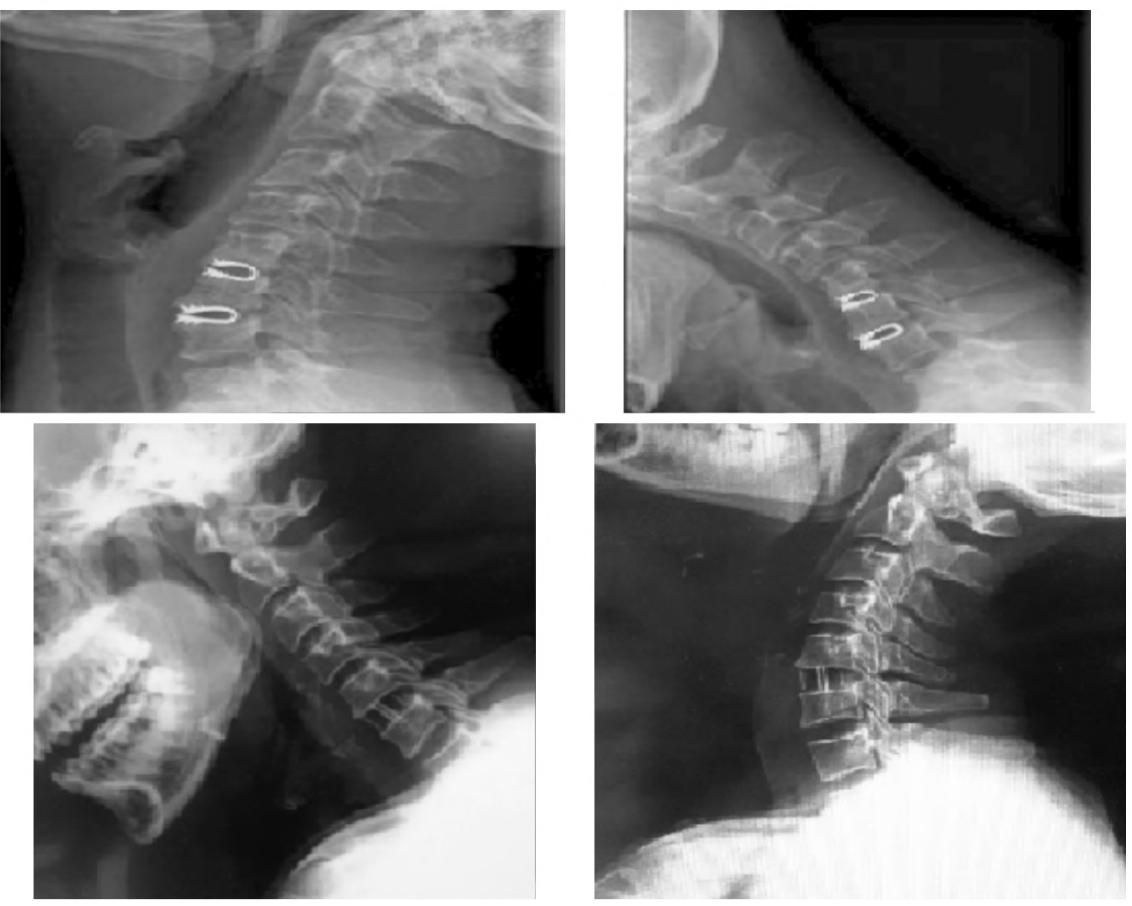

Fig. (5): Post operative dynamic study. 
The other studies revealed the same result data, confirming the effect of the dynamic method on the adjacent segment through reducing the spondylotic changes affecting it by preserving the movement [18].

Modic and associates in 1986 compared the accuracy of CT and MRI in evaluating patients with different cervical spine pathologies. They stated MRI was more sensitive than CT in identification of cervical spine pathology while CT was superior in distinguishing boney from soft tissue compressing elements. This was extremely helpful in planning our surgical procedure, as we have found that both CT and MRI were complimentary to each other for this purpose [15]

The collected data had showed no significant statistical results $(p>0.05)$ between the both study groups for the first year follow-up. While two year follow up had showed a significant statistical result $(p<0.05)$ of the radiological findings seen at the site of surgery and the adjacent level which is assessed based upon according to the original McAfee classification discussed before. ChristophMehren et al stated that the replaced level with the dynamic prosthesis does not delay the heterotopic ossification in a study of one-year follow-up, and so he suggested long term follow up for the grouped patient with such comparison study to emphasis or decline the actual result.

The range of motion was assessed at the operative level and the adjacent level, the movement assessed was flexion-extension, and lateral bending.

Yong-Hwan Cho, et al., stated that Recent publications of prospective randomized controlled trials comparing motion preserving implants with fusion suggest that patients with dynamic implants have a significantly lower risk of reoperations both at the index and adjacent level. At 5 years, patients treated with ACDF had a nearly 5-times higher reoperation rate due to adjacent segment disease. The present study focused on symptomatic adjacent-segment disease of the cervical spine, which we defined as the development of new radiculopathy or myelopathy referable to a motion segment adjacent to the site of a previous anterior cervical arthrodesis [21].

Cervical arthroplasty by DCI appears to be a good alternative for patients with symptomatic cervical radiculopathy and minimal cervical spondylosis. With good sensory and motor outcome through preserving the dynamic decompression reflected upon the neural foramen and canal stenosis as result of the spondylosis, osteophytes and ossi- fication formation at the same level and the adjacent segment. Arthroplasty may be associated with a lower rate of adjacent-level disease at 2 years, but further follow-up and analysis are needed to confirm this finding.

The DCI implant stabilizes the cervical spine while still providing stable, controlled motion allowing the spine to be functionally dynamic. Flexion and extension are allowed relative to a neutral position. After insertion, the implant works as a shock absorber to effectively prevent accelerated degeneration in the segments above and below the operated level.

\section{Conclusion:}

The following are the main conclusions that can be derived from this work:

1- Anterior cervical disc surgery with fusion accelerates adjacent-level degeneration by segmental loss of motion and abnormal biomechanical stress. This is why preservation of motion and prevention of adjacent degeneration is a major concern in spinal implant development with disc prosthesis.

2- This study indicates that the tested disc replacement device achieves 2-year results ranging from equivalent to superior in comparison to ACDF in the treatment of symptomatic cervical disc disease. Long-term maintenance of these results has not yet been determined.

3-The heterotopic ossification (HO) development was observed at 1 year after surgery and its progression was proportional to the elapsed postoperative time. Therefore, The Heterotopic Ossification must be expected during long-term followup, even the statistical results show significant prevalence of heterotopic ossification after two years follow up within the fixed group more than the dynamic group treated with the DCI device replacement.

4-Symptomatic adjacent-segment disease may affect more than one-fourth of all patients within ten years after an anterior cervical arthrodesis. Symptomatic adjacent level spondylosis and stenosis occurs in over $25 \%$ of patients within 8 to 10 years of ACDF, and many of these patients require additional surgery. Reported an adjacent level operation rate of $2.9 \%$ per year, and reported that at 10 years after cervical fusion. In our study average duration was 2.5 years revealing the early changes at the adjacent level, and so the long time research study is recommended for this study to augment other studies or not. 
5- As regard the range of motion with the flexion and extension the DCI implant shows a tendency to stabilize the segment while allowing some degree of residual mobility. In lateral bending, the implant significantly reduced movement, and thus stabilizes the affected segment. In the adjacent segments, the kinematics was not observed to be significantly affected and so delaying the spondylotic changes at both the target level and the adjacent segment.

6- Disc replacement with DCI is a new strategy. It is an intermediate solution in the spectrum of management strategies of cervical disc diseases. The changes made in the new larger food print shape of the new generation of DCI is said to decrease the rate of fusion. Delay fusion as long as possible is expected to prevent of ALD, The DCI implant stabilizes the cervical spine while still providing stable, controlled motion allowing the spine to be functionally dynamic. Flexion and extension are allowed relative to a neutral position. After insertion, the implant works as a shock absorber to effectively prevent accelerated degeneration in the segments above and below the operated level.

8- After insertion, the implant works as a shock absorber to effectively prevent accelerated degeneration in the segments above and below the operated level.

7- This study indicates that cervical disc replacement using the DCI at minimum, achieves equivalence when compared to ACDF by cage for the treatment of symptomatic cervical disc disease in patients with at least 2-year follow-up. Reduced neck, improved functions. As well as significant reduction in the rate of post-operative, early and long term complications. Whether these results will be maintained in the long-term and whether the implant will result in diminished rates of adjacent segment disc disease remains undetermined.

8- In summary, treating single or multiple level cervical disc disease with the DCI implant is a safe and easy procedure. Immediate dynamic stability with good clinical response and no implant-related morbidity or complications are the main advantages of this implant.

\section{References}

1- BRIGHAM C.D and TSAHAKIS P.J: Anterior cervical discectomy and fusion. Surgical technique and results. Spine, 20-7: 76-70, 1995.

2- DePALMA A.F., ROTHMAN R.H., LEWINNEK G.E. and CANALE S.T.: Anterior interbody fusion for severe cervical disc degeneration. Surg. Gnecol. Obstet., 134 (5): 755-8, 1972.
3- CLEMENTS D.H and O'LEARY P.F: Anterior cervical discectomy and fusion. Spine, 15-10: 1223-1025, 1990.

4- BENZEL E.C.: Biomechanics of Spine Stabilization. Rolling Meadows, American Association of Neurological Surgeons Publications, 2001.

5- MORGAN H. and ABOOD C.: Disc herniation at T1-2. Report of four cases and literature review. J. Neurosurg., 88: 148-150, 1998.

6- BLUMENKRANTZ N., SYLVEST J. and ASBOEHANSEN G.: Local low collagen content may allow herniation of intravertebral disc: Biochemical studies. Biochem. Med., 18: 283-290, 1977.

7- ZHONG JUN MO, et al.: Biomechanical effects of cervical arthroplasty with U-shaped disc implant on segmental range of motion and loading of surrounding soft tissue, 2013.

8- THOMPSON J.P., PEARCE R.H., SCHECHTER M.T., et al.: Preliminary evaluation of a scheme for grading the gross morphology of the human intervertebral disc. Spine, 15: 411-5, 1990.

9- ZDEBLICK T.A., WILSON D., COOKE M.E., KUNZ D.N., McCABE R., ULM M.J. and VANDERBY R.: Anterior cervical discectomy and fusion. A comparison of techniques in an animal model. Spine, 17 (10): s41826, 1992.

10- Artificial disc replacement combined with fusion verses two-level fusion in cervical two-level disc disease. DONG et al. Spine Vol., 34, 2009.

11- TOMARAS C.R., BLACKLOCK J.B., PARKER W.D. and HARPER R.L.: Outpatient surgical treatment of cervical radiculopathy. J. Neurosurg., 87 (1): 41-3.

12- SAAL J.S., SAAL J.A. and YURTH E.F.: Nonoperative management of herniated cervical intervertebral disc with radiculopathy. Spine Aug., 15; 21 (16): 1877-83, 1996.

13- SAKARI S. and JAAKKO R.: Hernesniemi: A prospective randomized study of single level cervical disc operations with long term follow-up. Neurosurg., 43 (1): 51-55, 1998.

14- STEWART T.J., SCHLENK R.P. and BENZEL E.C.: Multiple level discectomy and fusion. Neurosurgery, 60: s-143-s-148, 2007.

15- CHANG J.C., PARK H.K. and CHOI S.K.: Posterior Cervical Inclinatory Foraminotomy for Spondylotic Radiculopathy Preliminary. J. Korean Neurosurg. Soc., 49 (5): 308-13. Epub, 2011.

16- SOO EON LEE, et al.: Early development and progression of heterotopic ossification in cervical total disc replacement, 16: 31-36, 2012.

17- SCHLENK R.P., STEWART and BENZEL E.C.: The biomechanics of iatrogenic spinal destabilization and implant failure Neurosurg Focus, 15 (3): Article 2, 2003.

18- RAYNOR R.B.: Anterior or posterior approach to the cervical spine: an anatomical and radiographic evaluation and comparison. Neurosurgery, 12 (1): 7-13, 1983.

19- SAAL J.S., SAAL J.A. and YURTH E.F.: Nonoperative management of herniated cervical intervertebral disc with radiculopathy. Spine Aug., 15; 21 (16): 1877-83, 1996. 
20- SCOVILLE W.B. and WHITCOMB B.B.: Lateral rupture of cervical intervertebral disks. Postgrad Med., 39: 174$180,1966$.
21- STEWART T.J., SCHLENK R.P. and BENZEL E.C.: Multiple level discectomy and fusion. Neurosurgery, 60: s-143-s-148, 2007.

\section{دراسة مقارنة لحالات جراحة الغضروف العنقى عن طريق التثبيت الاستاتيكى العيكي

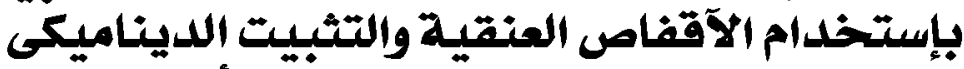

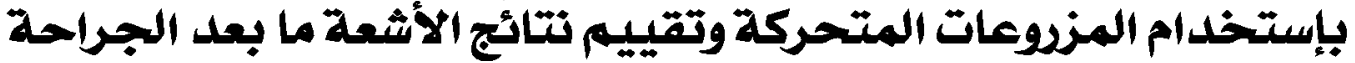

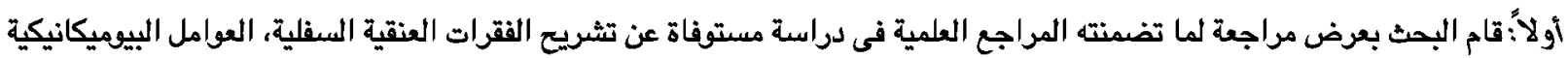

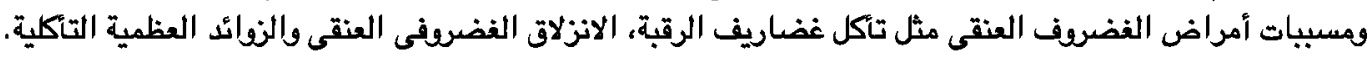

قدم البحث شرح لطرق التشخيص الإكلينيكية وقد تضمن البحث تحليل لتاريخ وأعراض أمراض الفضروف العنقى . بعد ذلك قدم البحث

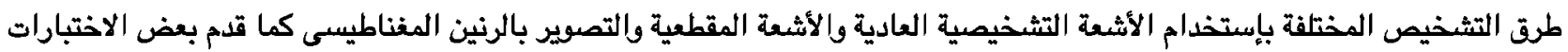
الكهروفيسيوليجية.

كما قام البحث بعرض طرق العلاج الغير جراحية مثل العلاج الدوائى والعلاج الطبيعى، ثم عرض البحث مختلف طرق التدخل الجراحي

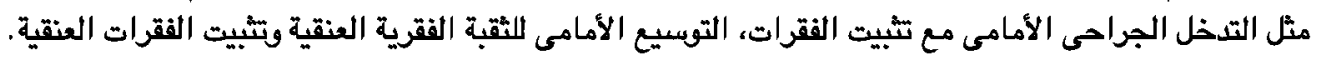

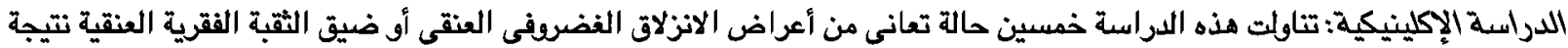

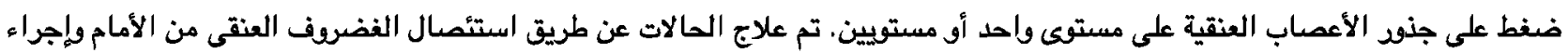

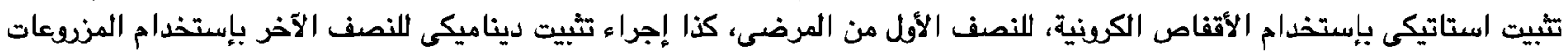

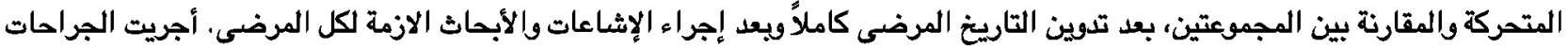

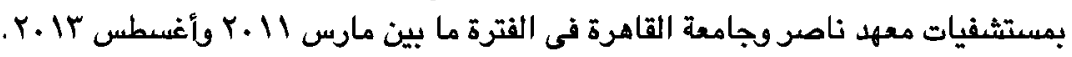
وقد كان متوسط فترة المتابعة الحالات اثنا وعشرين ونصف شهراً ولم تحدث أية مضاعفات أثناء فترة المتابعة وقد تم استباط النتائج النهائية الحالات بعد اثنى عشر شهراً من إجراء الجرات الجراحة.

$$
\text { ويمكن استخلاص ما يلى من الدراسة: }
$$

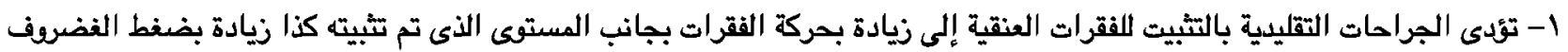

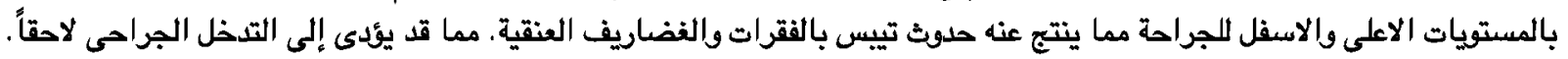
ז- تظهر أعراض الضغط على الأعصاب أو الحبل الشوكى بالمستوى الموازى لمكان التخخل بالتّبيت الاستاتيكى بمرود الوقت، حيث تحدث

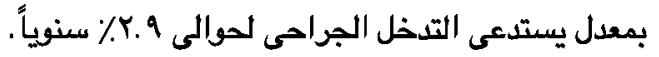
ץ- أظهرت النتائج لما بعد إجراء الجراحات بالطريقتين الاستاتيكية تحسن أعلى بمستوى الاحساس والصركة اللحالات المستخدم فيها التشييت

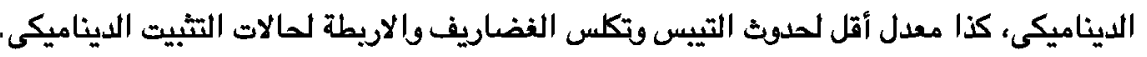
ع- يعد التشييت الديناميكى بإستخدام المزدوعات المتحركة بديلاً أمناً وبسيطاً للتَبيت الاستاتيكى، حيث يعمل على حفظ حركة الفقرات وإمتصاص

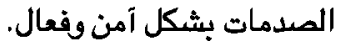

